\title{
VIABILIDADE DO CONTROLE QUÍMICO DE DOENÇAS FOLIARES EM HÍBRIDOS DE MILHO NO PLANTIO DE SAFRINHA ${ }^{1}$
}

\author{
GONÇALVES, Maria Eugênia Mattar Pimenta ${ }^{2}$ \\ GONÇALVES JÚNIOR, Djalma ${ }^{3}$ \\ SILVA, Alessandro Guerra da ${ }^{4}$ \\ CAMPOS, Hércules Diniz ${ }^{5}$ \\ SIMON, Gustavo André ${ }^{6}$ \\ SANTOS, Catarina José de Lima ${ }^{7}$ \\ SOUSA, Marliana Araújo de ${ }^{7}$
}

\begin{abstract}
RESUMO: Com o objetivo de avaliar a resposta de diferentes híbridos de milho, à aplicação de fungicida, em diferentes estádios fenológicos, foi instalado um experimento no município de Montividiu, GO, durante a safrinha de 2007. O delineamento experimental utilizado foi de blocos casualizados, em esquema fatorial $3 \times 4$, com quatro repetições, correspondendo a três híbridos de milho (AG 7000, Impacto e P30K75) e três estádios de aplicação de fungicida (VT, R1 e VT+R1), acrescido da testemunha sem a aplicação de fungicida. Quando realizou-se uma aplicação de fungicida, empregou-se $0,75 \mathrm{~L} \mathrm{ha}^{-1}$ do piraclostrobina + epoxiconazole; quando foram realizadas duas aplicações, foi utilizado $0,5 \mathrm{~L} \mathrm{ha}^{-1}$ do mesmo fungicida em cada uma das épocas (VT e R1). Na safrinha, não houve acréscimo de rendimentos com a aplicação de fungicida no híbrido Impacto, constatando efeitos benéficos do fungicida nos híbridos AG 7000 e P30K75. As maiores rentabilidades foram obtidas, para estes dois híbridos, com aplicação do fungicida em VT+R1. O uso de fungicida em VT+R1 proporcionou aumento do peso mil grãos e do número de grãos por espiga, reduzindo a incidência de grãos ardidos e de acamamento de plantas. Não foram constatadas diferenças significativas entre o uso de fungicida e a testemunha para incidência e severidade de doenças foliares.
\end{abstract}

Palavras-chave: Zea mays L. Fungos. Fungicidas. Características sanitárias.

\section{FEASIBILITY OF CHEMICAL CONTROL OF LEAF DISEASES IN HYBRIDS OF CORN IN PLANTING THE LATTER SEASON}

\begin{abstract}
SUMMARY: In order to evaluate the response of different hybrids of maize, the application of fungicide at different phenological stages an installed was experiment in the municipality of Montividiu, GO, during the latter season of 2007. The experimental design of was randomized blocks in factorial scheme $3 \times 4$, with four replicates, corresponding to three hybrids of maize (AG 7000, Impact and P30K75) and three stages of application of fungicide (VT, VT and R1 + R1), plus the witness without the application of fungicide. When you place an application of fungicide, using $0.75 \mathrm{~L}$ ha-1 of pyraclostrobin + epoxiconazole, when two applications were made, we used $0.5 \mathrm{~L}$ ha1 of the same fungicide in each season (VT and R1 ). In the latter season, there was no increase in income with the application of fungicide in hybrid impact, noting the beneficial effects of the fungicide in hybrid AG 7000 and P30K75. The highest returns were obtained for these two hybrids with application of fungicide at R1 + VT. The use of fungicide in VT + R1 increased from one thousand grain weight and number of grains per spike, reducing the incidence of grain rot and lodging of plants. There were no significant differences between the use of fungicide to control and incidence and severity of leaf diseases.
\end{abstract}

Keywords: Zea mays L.. Fungi. Fungicide. Features health.

\footnotetext{
${ }^{1}$ Parte da Dissertação de Mestrado em Produção Vegetal (FESURV) do primeiro autor

${ }^{2}$ Prof. M. Sc. Fitotecnia. Faculdade de Luis Eduardo Magalhães -BA. mariaeugeniamattar@hotmail.com

${ }^{3}$ Prof. M. Sc. Fitotecnia. Faculdade de Luis Eduardo Magalhães -BA. djalmagoncalvesjr@gmail.com

${ }^{4}$ Prof. Dr. Fitotecnia. Professor Adjunto II da Universidade de Rio Verde - FESURV. silvaag@ yahoo.com.br

${ }^{5}$ Prof. Dr. Fitopatologia. Professor Titular da Universidade de Rio Verde - FESURV. campos@ fesurv.br

${ }^{6}$ Prof. Dr. Gen. e M. de Plantas. Professor Adjunto da Universidade de Rio Verde - FESURV. simon@ fesurv.br

${ }^{7}$ M. Sc. Produção Vegetal - FESURV.catarinasantosb@yahoo.com.br; marlianaaraujo@ hotmail.com
} 


\section{INTRODUÇÃO}

As doenças foliares de maior incidência na cultura do milho são: a cercosporiose (Cercospora zeamaydis); mancha foliar de exserohilum (Exserohilum turcicum); mancha de phaeosphaeria (Phaeosphaeria maydis); ferrugem polysora (Puccinia polysora); ferrugem comum (Puccinia sorghi); e mancha de diplódia (Diplodia macrospora) (EMBRAPA, 2007).

O número e o momento da aplicação de fungicidas na cultura do milho, além da resistência dos híbridos, são essenciais para definir o período efetivo dos fungicidas (PEF). Ward; Laing ; Rijkenberg (1997) observaram que os fungicidas sistêmicos, como os triazóis e os benzimidazóis, com maior PEF, resultaram em maior rendimento de grãos.

O emprego de fungicidas na cultura do milho tem proporcionado melhoria no desenvolvimento das plantas e aumento de rendimentos, com produtos disponíveis no mercado, apresentando diferentes períodos de ação nas plantas de milho. Neste sentido, deve-se conhecer o PEF, definido como o período no qual, após sua aplicação, há um mínimo de aumento da doença (SOUZA ; BRAGA, 2004). O PEF variou com a resistência dos híbridos e a época de aplicação do fungicida, observando 45 dias de PEF para os híbridos resistentes para Phaeosphaeria maydis e Cercosporazea-maydis e de 30 dias para os híbridos suscetíveis, (SOUZA; BRAGA, 2004).

Segundo Casa; Reis ; Blum (2008), o número e o momento da aplicação de fungicidas na cultura do milho, além da resistência dos híbridos, são essenciais para definir o período efetivo do fungicida (PEF).

Segundo Berger (1981), os fungicidas aplicados via pulverização foliar, na cultura do milho, interrompem o progresso da doença logo após a pulverização e seu efeito permanece por, aproximadamente, 15 dias, podendo este variar em razão das condições climáticas, tecnologia de aplicações, estádio fenológico da cultura, etc. $\mathrm{O}$ autor destacou ainda que os fungicidas sistêmicos proporcionam PEF mais longo em relação aos fungicidas protetores, o que os tornam mais eficientes no controle das doenças.

A feosféria Phaeosphaeria maydis é uma doença que pode reduzir significativamente a área foliar da planta de milho em cultivares suscetíveis. Tem-se demonstrado haver diferenças significativas no rendimento de grãos comparando-se cultivares, locais e épocas de semeadura (SAWAZAKI et al.; 1997; BRASIL; CARVALHO, 1998). Pereira; Silva; Rezende (1993) destacam que a incidência de Exserohilum turcicum provoca aumento do tombamento das plantas de milho, ocasionando redução no rendimento de grãos.

Os danos associados às doenças foliares são decorrentes do mau funcionamento e da destruição dos tecidos fotossintéticos, devido ao aumento do número e da área das lesões, determinando a necrose na folha. Esse sintoma, seguido da necrose prematura das folhas, limitam o desenvolvimento de grãos (FANTIN; DUARTE ; SAWAZAKI, 2005).

O sucesso do controle das doenças, com a aplicação de fungicidas na cultura do milho está condicionado ao momento da aplicação. Para Cercospora zea-maydis, a porcentagem de infecção deve ser preferencialmente próxima a $1 \%$ (nível muito baixo), e quando as condições climáticas são favoráveis à doença, sugere-se efetuar mais de uma aplicação de fungicida para um controle satisfatório (FANTIN; DUARTE ; SAWAZAKI, 2005). Ward; Laing; Rijkenberg (1997) constataram que o período mais efetivo de controle da cercosporiose e os maiores rendimentos de grãos de milho foram obtidos com pulverizações entre $2 \%$ a $3 \%$ de severidade na planta, na folha da espiga, em intervalos de 14 dias até à maturidade fisiológica dos grãos.

Nucleus, v.9, n.1, abr.2012 


\section{MATERIAL E MÉTODOS}

O ensaio foi instalado em área de cultivo comercial, sistema de plantio direto, na fazenda Pindaíbas, no município de Montividiu, GO, na safrinha de 2007. A altitude local é de 936m, com coordenadas $17^{\circ} 30^{\prime} \mathrm{S}$ e $51^{\circ} 16^{\prime} \mathrm{W}$, EMBRAPA (1999). O solo foi classificado como Latossolo vermelho - escuro, de textura média (areno-argiloso) com aproximadamente $1 \%$ de declividade cultivado no sistema de plantio direto. A precipitação média anual é de $1600 \mathrm{~mm}$, com temperatura média anual mínima de $20^{\circ} \mathrm{C}$ e máximura de $35^{\circ} \mathrm{C}$.

Foi empregado o delineamento de blocos casualizados, em esquema fatorial $3 \times 4$, composto pelos três híbridos de milho (AG700, Impacto e P30K75) e três épocas de aplicação de fungicida (VT, R1, VT+R1), acrescido dos três híbridos de milho sem aplicação de fungicida. O híbrido AG7000 foi desenvolvido para apresentar excelentes resultados em diferentes altitudes e épocas de plantio. Nas regiões acima de $700 \mathrm{~m}$ de altitude, o AG7000 é a melhor alternativa contra o ataque de doenças foliares, principalmente a cercospora e também apresenta excelente qualidade de grãos. Nas regiões abaixo de 700 $\mathrm{m}$ de altitude, ele é tolerante a doença como Puccinia polysora, Phaeosphaeria maydis e E. turcicum. Além disso, ele oferece alta estabilidade produtiva e resistência ao acamamento, principalmente nos plantios de época snormal e tardio. Híbrido simples, precoce, grãos alaranjados e grãos duros. Já o híbrido P30K75, apresenta-se como híbrido simples modificado, e precocidade na colheita com flexibilidade de plantio e tolerância à Cercospora zea-maydis, grãos alaranjados e semiduro, alto potencial produtivo, ampla adaptação geográfica, tolerância a cercospora e phaeosphaeria, pendoamento precoce. O híbrido Impacto caracteriza-se pela excepcional sanidade foliar para as principais doenças, com destaque em relação à Cercospora zea-maydis, proporcionando grandes performances em verão na região central do Brasil. híbrido simples, precoce, grãos alarenjados e duro.

Cada parcela constituiu de seis linhas de 5,0 $\mathrm{m}$ de comprimento, espaçadas 0,75 $\mathrm{m}$ entre si na safrinha e espaçada $0,76 \mathrm{~m}$ entre si para a safra verão, sendo a área útil composta por considerada 2 fileiras centrais, de 4,0 m de comprimento, eliminando $0,5 \mathrm{~m}$ de cada extremidade, com um estande equivalente a 66.000 plantas ha $^{-1}$. Para a aplicação do fungicida, na safrinha foi utilizado um pulverizador costal pressurizado a $\mathrm{CO}_{2}$, com barra cobrindo uma faixa de $3 \mathrm{~m}$, composta de seis bicos, tipo leque duplo TJ 100.02, espaçados de $0,5 \mathrm{~m}$. O volume de calda utilizado foi equivalente a $200 \mathrm{~L} \mathrm{ha}^{-1}$ e pressão de $30 \mathrm{lb}$ pol $^{-2}$. Foram realizadas duas pulverizações com o produto epoxiconazole + pyraclostrobin: a primeira aplicação foi realizada quando a planta estava no estádio VT (pendoamento), na dose de $0,75 \mathrm{~L} \mathrm{ha}^{-1}$, a segunda no estádio R1 (florescimento), na dose de $0,75 \mathrm{~L} \mathrm{ha}^{-1}$, para a época VT + R1 realizou duas aplicações na dose de $0,5 \mathrm{~L} \mathrm{ha}^{-1}$.

$\mathrm{Na}$ área experimental, a adubação foi realizada de acordo com a análise de solo, (anexos 1 e 2). Retiraram - se amostras de solo nas profundidades de 0-10 e de $10-20 \mathrm{~cm}$.

Foi realizado o tratamento de sementes no dia da semeadura, com 2,0 L $100 \mathrm{~kg}^{-1} \mathrm{de}$ sementes de

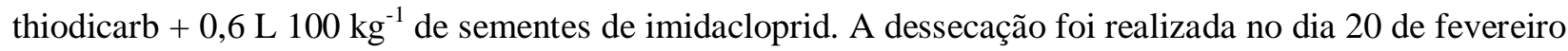
de 2007, utilizando 2,5 $\mathrm{L} \mathrm{ha}^{-1}$ glyphosate $+0,05 \mathrm{~L} \mathrm{ha}^{-1}$ lambdacyhalothrin $+1 \mathrm{~kg}$ de ácido bórico $+0,25 \mathrm{~L}$ $\mathrm{ha}^{-1}$ óleo mineral, com um volume de calda de $200 \mathrm{~L} \mathrm{ha}^{-1}$.

A semeadura foi realizada em 21 de fevereiro de 2007, utilizando uma semeadora pneumática para o sistema plantio direto com 6 linhas, emergindo no dia 28 de fevereiro de 2007. A adubação foi realizada no momento da implantação do ensaio, com emprego, a lanço, de $200 \mathrm{~kg} \mathrm{ha}^{-1}$ de 06-12-06. Foi feita uma cobertura nitrogenada de $200 \mathrm{~kg} \mathrm{ha}^{-1}$ de uréia, sendo aplicada quando as plantas apresentavam com 3 a 4 folhas totalmente expandidas. 
O controle de plantas daninhas foi realizado com uso de 4,5 $\mathrm{L} \mathrm{ha}^{-1}$ de atrazine, em pré emergência e atrazina + Nicosulfuron + nimbus com dose de 2,5 L + 0,4 L + 2\%, aos 38 DAE.

Para auxiliar o controle de pragas, foram realizadas quatro pulverizações: a primeira aos $25 \mathrm{DAE}$, com os inseticidas lufenuron + methomyl na dose de $0,3 \mathrm{~L}+0,6 \mathrm{~L} \mathrm{ha}^{-1}$, a segunda realizada aos $38 \mathrm{DAE}$, para o controle de Spodoptera frugiperda com Lambdacialotrina + Lufenuron nas doses de 0,05 L + 0,25 $\mathrm{L} \mathrm{ha}^{-1}$, terceira aplicação realizada aos $49 \mathrm{DAE}$ utilizando methomyl + óleo mineral nas doses: 0,8 L + 0,3 $\mathrm{L} \mathrm{ha}^{-1}$, quarta aplicação realizada aos $68 \mathrm{DAE}$ utilizando os seguintes produtos methomyl + óleo mineral, nas doses: 0,8 L + 0,3 $\mathrm{L} \mathrm{ha}^{-1}$, com um volume de calda de $200 \mathrm{~L} \mathrm{ha}^{-1}$.

As características avaliadas na área útil das parcelas na safrinha foram: a) Incidência e severidade de doenças: as avaliações foram realizadas nos estádios VT (pendoamento), R2 (grãos leitosos), R4 (grão farináceo) e R5 (grãos farináceo-duro), em cinco plantas amostradas aleatoriamente. No estádio VT, essas avaliações foram feitas no terço inferior da planta. Nas demais avaliações, foram realizadas na folha da espiga; severidade de doenças, atribuindo notas segundo a escala de Hilty; Hadden ; Garden (1979): 0: sem sintoma; 1 : poucas lesões nas folhas abaixo da espiga e nenhuma lesão acima; 2: muitas lesões nas folhas abaixo da espiga e poucas lesões acima; 3: severo desenvolvimento de lesões nas folhas abaixo da espiga e todas as folhas acima da espiga com lesões; 4: todas as folhas com severo desenvolvimento de lesões, mas tecido verde ainda visível; 5: todas as folhas secas e mortas.

b) Altura de plantas e de inserção da espiga: medição do colo até à extremidade do pendão e da inserção da espiga, respectivamente, em cinco plantas amostradas aleatoriamente, expressando os resultados em metros;

c) Acamamento e quebramento: contagem das plantas tombadas e quebradas (quebramento abaixo da inserção da espiga) no momento da colheita, apresentando os resultados em porcentagem;

d) Número de grãos por espiga: contagem do número médio de grãos em cinco espigas amostradas aleatoriamente;

e) Peso de mil grãos: pesagem de amostra de 1.000 grãos corrigindo a umidade para 13\%;

f) Grãos ardidos: contagem do número de grãos ardidos em três amostras de 100 grãos de cada parcela, expressando os resultados em porcentagem, analisados visualmente;

g) Rendimento de grãos: colheita e trilha das espigas, com posterior pesagem dos grãos, corrigindo a umidade para $13 \%$ e transformando os dados para $\mathrm{kg} \mathrm{ha}^{-1}$;

h) Rentabilidade da aplicação do fungicida: análise da rentabilidade da aplicação de fungicida para cada híbrido de milho, levando-se em consideração o rendimento de grãos, o valor de R \$74,00 o litro do fungicida utilizado, $\mathrm{R} \$ 18,00$ a saca de milho no momento da colheita na safrinha, e o custo de aplicação de $\mathrm{R} \$ 20,00 \mathrm{ha}^{-1}$.

A fórmula utilizada para calcular a rentabilidade segue descrita abaixo:

$$
\mathrm{R}=(((\underline{\mathrm{Rn}-\mathrm{Rt}})) \cdot \mathrm{Ps})-(\mathrm{Df} \cdot \mathrm{Pf}+\mathrm{Cap})
$$

60

onde:

$\mathrm{R}$ - rentabilidade, em $\mathrm{R} \$ \mathrm{ha}^{-1}$;

$\mathrm{Rn}$ - rendimento do tratamento com fungicida $\mathrm{n}, \mathrm{em} \mathrm{kg} \mathrm{ha}^{-1}$;

Rt- rendimento obtido na testemunha, em kg ha ${ }^{-1}$;

Ps- preço da saca de milho, em R \$;

Df- dose do fungicida, em litros;

Pf- preço do litro do fungicida, em R\$;

Cap- custo operacional da aplicação, em $\mathrm{R} \$ \mathrm{ha}^{-1}$;

Nucleus, v.9, n.1, abr.2012 
i) AACPD: Para calcular a severidade das doenças ao longo do tempo, foi calculada a área abaixo da curva de progresso da doença (AACPD), que foi calculada a partir da curva de progresso da doença, com base nos dados de severidade obtidos em cada avaliação, segundo Campbell ; Madden (1990).

Segundo Shaner; Finney (1977), a área abaixo da curva de progresso da doença pode ser calculada da seguinte forma:

$$
\mathrm{AACPD}=\sum_{i=1}^{n}\left[\left(\mathrm{Y}_{\mathrm{i}+1}+\mathrm{Y}_{\mathrm{i}}\right) / 2\right]\left[\mathrm{X}_{\mathrm{i}+1}-\mathrm{X}_{\mathrm{i}}\right]
$$

Em que:

$\mathrm{Y}_{\mathrm{i}}$ : severidade da doença (nota por parcela em \%) na iésima observação;

$\mathrm{Y}_{\mathrm{i}+1}$ : severidade da doença na época da avaliação i+1;

$\mathrm{X}_{\mathrm{i}}$ : tempo (dias) na iésima observação;

$\mathrm{X}_{\mathrm{i}+1}$ : época da avaliação $\mathrm{i}+1$;

n: número total de observações.

A AACPD foi padronizada ao dividir o valor da área abaixo da curva de progresso da doença pela duração de tempo total ( Tn - T1) da epidemia de diferentes durações, CAMPBELL ; MADDEN (1990).

As análises estatísticas foram realizadas para todas as características citadas anteriormente, exceto rentabilidade, sendo efetuada, inicialmente, a análise de variância. Empregou-se o teste de Tukey a 5\% de probabilidade para a comparação entre as médias dos tratamentos quando constatada significância para a variável analisada, utilizando o programa estatístico SISVAR (FERREIRA, 2000). Foram realizadas as análises de correlações para todas as características analisadas, utilizando o programa estatístico Genes (CRUZ, 1997).

\section{RESULTADOS E DISCUSSÃO}

Os dados climáticos (precipitação e temperatura) durante e após condução do ensaio no período de outubro de 2007 a março de 2008, estão apresentados na figura 1.

Figura 1. Valores médios de temperatura e precipitação durante e após a condução do experimento, em Montividiu,GO.

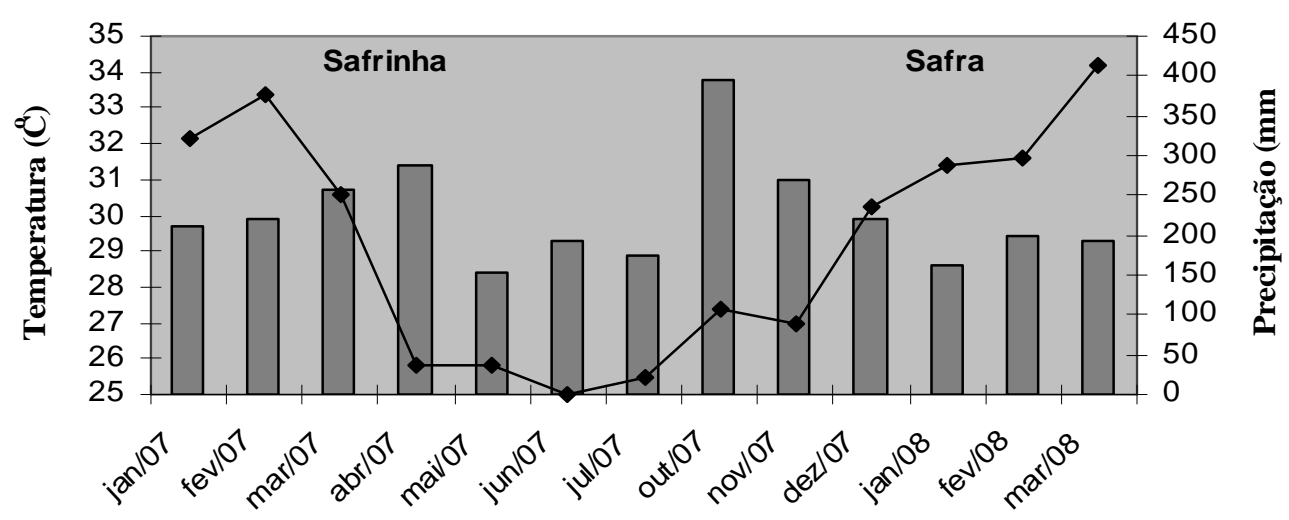

Meses do Ano

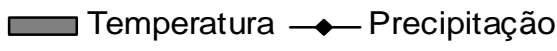

Fonte: Estação Experimental

As doenças observadas durante a condução do experimento foram: cercosporiose (Cercospora zea-maydis), mancha foliar de exserohilum (Exserohilum turcicum), mancha de phaeosphaeria 
(Phaeosphaeria maydis), ferrugem polysora (Puccinia polysora), ferrugem comum (Puccinia sorghi) e mancha de diplódia (Diplodia macrospora), EMBRAPA (2007).

$\mathrm{Na}$ avaliação da incidência de doenças no estádio VT, não foram constatadas diferenças significativas entre a ausência ou a aplicação de fungicida em cada híbrido de milho até o estádio R5 das plantas, o mesmo sendo observado para severidade até R3. Apesar de ter sido constatada diferença significativa em R5 com a aplicação de fungicida, a porcentagem de doenças no híbrido Impacto ainda foi baixa (Tabela 1).

Tabela 1. Valores médios de incidência de doenças em (\%) dos híbridos AG 7000, Impacto e P30K75 em função da aplicação de fungicida, na safrinha de 2007

\begin{tabular}{|c|c|c|c|c|}
\hline Híbridos & Testemunha & VT & R1 & VT+R1 \\
\hline \multicolumn{5}{|c|}{ Incidência VT } \\
\hline AG7000 & $1,2 \mathrm{Aa}$ & $1,0 \mathrm{Aa}$ & $0,8 \mathrm{Aa}$ & 1,4 Aa \\
\hline Impacto & $0,9 \mathrm{Aa}$ & $0,8 \mathrm{Aa}$ & $1,1 \mathrm{Aa}$ & $0,9 \mathrm{Aa}$ \\
\hline P30K75 & $1,0 \mathrm{Aa}$ & $0,7 \mathrm{Aa}$ & $0,8 \mathrm{Aa}$ & $0,5 \mathrm{Aa}$ \\
\hline \multicolumn{5}{|c|}{ Incidência R1 } \\
\hline AG7000 & $0,9 \mathrm{Aa}$ & 1,0 Aa & $1,0 \mathrm{Aa}$ & 1,1 Aa \\
\hline Impacto & $1,1 \mathrm{Aa}$ & $0,8 \mathrm{Aa}$ & $1,3 \mathrm{Aa}$ & 1,0 Aa \\
\hline $\mathrm{P} 30 \mathrm{~K} 75$ & $1,5 \mathrm{Aa}$ & $1,2 \mathrm{Aa}$ & $1,0 \mathrm{Aa}$ & $0,7 \mathrm{Aa}$ \\
\hline \multicolumn{5}{|c|}{ Incidência R2 } \\
\hline AG7000 & $0,3 \mathrm{Aa}$ & $0,4 \mathrm{Aa}$ & $0,2 \mathrm{Aa}$ & $0,1 \mathrm{Aa}$ \\
\hline Impacto & $0,2 \mathrm{Aa}$ & $0,3 \mathrm{Aa}$ & $0,4 \mathrm{Aa}$ & $0,1 \mathrm{Aa}$ \\
\hline $\mathrm{P} 30 \mathrm{~K} 75$ & $0,7 \mathrm{Aa}$ & $0,7 \mathrm{Aa}$ & $0,3 \mathrm{Aa}$ & $0,2 \mathrm{Aa}$ \\
\hline \multicolumn{5}{|c|}{ Incidência R3 } \\
\hline AG7000 & $0,9 \mathrm{Aa}$ & $1,3 \mathrm{Aa}$ & $1,1 \mathrm{Aa}$ & 1,2 Aa \\
\hline Impacto & $1,5 \mathrm{Aa}$ & $0,9 \mathrm{Aa}$ & $1,3 \mathrm{Aa}$ & 1,1 Aa \\
\hline P30K75 & 1,3 Aa & $1,4 \mathrm{Aa}$ & $1,1 \mathrm{Aa}$ & $0,9 \mathrm{Aa}$ \\
\hline \multicolumn{5}{|c|}{ Incidência R5 } \\
\hline AG7000 & $0,7 \mathrm{Ab}$ & $1,1 \mathrm{Aa}$ & $1,0 \mathrm{Aa}$ & $0,9 \mathrm{Aa}$ \\
\hline Impacto & $1,7 \mathrm{Aa}$ & 1,0 Aa & $1,4 \mathrm{Aa}$ & $0,9 \mathrm{Aa}$ \\
\hline P30K75 & 1,4 Aab & $0,9 \mathrm{Aa}$ & $1,0 \mathrm{Aa}$ & $0,9 \mathrm{Aa}$ \\
\hline
\end{tabular}

*Médias seguidas de mesma letra minúscula na coluna e maiúscula na linha, dentro de cada variável,não diferem entre si pelo teste Tukey, a 5\%, de probabilidade.

Mesmo assim, esses resultados são considerados baixos, pois as condições climáticas foram desfavoráveis ao desenvolvimento dos patógenos. O fator ambiente, nessa época de avaliação, foi determinante para a baixa ocorrência e desenvolvimento da doença, revelando que as condições ambientais foram desfavoráveis à ocorrência da mesma. Para o desenvolvimento das doenças, são necessários períodos de temperaturas máximas entre $30^{\circ} \mathrm{C}$, mínimas inferiores a $16^{\circ} \mathrm{C}$, aliados a uma umidade relativa superior a 60\%. Fernandes ; Oliveira, 1997; relatam que essas condições ambientais são suficientes para o desenvolvimento de epidemias da doença. Outras doenças também podem causar danos diretos na produção de milho. Pereira; Silva ; Rezende (1993) destacam que a incidência de Exserohilum turcicum provoca aumento do tombamento das plantas de milho, ocasionando redução no rendimento de grãos.

Fantin; Duarte ; Sawazaki (2005) compararam épocas e número de aplicações do fungicida estrobirulinas + triazóis no controle de Phaeosphaeria maydis e Cercospora zea-maydis em híbridos de 
milho resistentes e suscetíveis cultivados na safrinha em várias localidades. Os autores observaram redução na severidade das doenças com a aplicação do fungicida. Segundo Morandi et al. (2002), em quatro e três aplicações em intervalos quinzenais, os fungicidas azoxystrobin, fluquinconazole, epoxiconazole + pyraclostrobin e propiconazole reduziram significativamente a severidade da Cercospora zea-maydis. Em duas e uma aplicação, apenas azoxystrobin e epoxiconazole + pyraclostrobin reduziram a doença.

A cercosporiose é aumentada em condições de alta umidade relativa e temperatura diurna variando de moderada a alta, com noites frias associada à formação de orvalho. Além disso a presença de dias nublados ou chuvosos favorecem o desenvolvimento da doença.

$\mathrm{Na}$ análise da severidade das doenças foliares, verificou-se em VT (momento da primeira aplicação), que as médias dos tratamentos de fungicidas e híbridos de milho não diferiram-se entre si (Tabela 2).

Tabela 2. Valores médios de severidade de doenças em (\%) dos híbridos AG 7000, Impacto e P30K75 em função da aplicação de fungicida, na safrinha de 2007

\begin{tabular}{|c|c|c|c|c|}
\hline Híbridos & Testemunha & VT & R1 & $\mathrm{VT}+\mathrm{R} 1$ \\
\hline \multicolumn{5}{|c|}{ Severidade VT } \\
\hline AG7000 & $1,5 \mathrm{Aa}$ & 2,5 Aa & $2,1 \mathrm{Aa}$ & 2,8 Aa \\
\hline Impacto & $1,4 \mathrm{Aa}$ & $1,3 \mathrm{Aa}$ & $1,3 \mathrm{Aa}$ & $1,4 \mathrm{Aab}$ \\
\hline P30K75 & $2,2 \mathrm{Aa}$ & 2,0 Aa & $1,1 \mathrm{Aa}$ & $1,0 \mathrm{Ab}$ \\
\hline \multicolumn{5}{|c|}{ Severidade R1 } \\
\hline AG7000 & $1,0 \mathrm{Aa}$ & $0,9 \mathrm{Aa}$ & 1,0 Aa & 1,0 Aa \\
\hline Impacto & $1,5 \mathrm{Aa}$ & $0,9 \mathrm{Aa}$ & 0,9 Аа & 0,9 Aa \\
\hline P30K75 & $1,6 \mathrm{Aa}$ & $1,3 \mathrm{Aa}$ & $1,1 \mathrm{Aa}$ & $1,0 \mathrm{Aa}$ \\
\hline \multicolumn{5}{|c|}{ Severidade R2 } \\
\hline AG7000 & $1,7 \mathrm{Aa}$ & 2,5 Aa & 2,5 Aa & 3,5 Aa \\
\hline Impacto & $1,1 \mathrm{Aa}$ & $0,5 \mathrm{Ab}$ & $0,9 \mathrm{Aa}$ & $0,6 \mathrm{Ab}$ \\
\hline $\mathrm{P} 30 \mathrm{~K} 75$ & $1,5 \mathrm{Aa}$ & $2,4 \mathrm{Aa}$ & $0,8 \mathrm{Aa}$ & $0,9 \mathrm{Ab}$ \\
\hline \multicolumn{5}{|c|}{ Severidade $\mathbf{R 3}$} \\
\hline AG7000 & $1,0 \mathrm{Aa}$ & $1,0 \mathrm{Aa}$ & $0,9 \mathrm{Aa}$ & 1,0 Aa \\
\hline Impacto & $1,4 \mathrm{Aa}$ & $0,8 \mathrm{Aa}$ & $1,1 \mathrm{Aa}$ & 1,1 Aa \\
\hline P30K75 & $1,7 \mathrm{Aa}$ & $1,5 \mathrm{Aa}$ & $1,4 \mathrm{Aa}$ & $1,2 \mathrm{Aa}$ \\
\hline \multicolumn{5}{|c|}{ Severidade R5 } \\
\hline AG7000 & $0,8 \mathrm{Ab}$ & 1,0 Aa & $0,9 \mathrm{Aa}$ & $0,7 \mathrm{Aa}$ \\
\hline Impacto & $1,8 \mathrm{Aa}$ & $0,6 \mathrm{Ba}$ & 1,2 Aab & 1,0 Aba \\
\hline P30K75 & 1,5 Aab & $1,2 \mathrm{Aa}$ & $1,1 \mathrm{Aa}$ & $1,0 \mathrm{Aa}$ \\
\hline
\end{tabular}

*Médias seguidas de mesma letra minúscula na coluna e maiúscula na linha, dentro de cada variável,não diferem entre si pelo teste Tukey, a 5\%, de probabilidade.

Nas avaliações realizadas em R1 e R2, constatou-se que o fungicida não aumentou a severidade das doenças foliares, sendo que os tratamentos que receberam aplicação apresentaram valores menores em relação à respectiva testemunha: O AG7000 em R3 e R5. Já os híbridos Impacto e P30K75 apresentaram menor severidade na testemunha. Isso pode ser atribuído a ausência do efeito do fungicida aos 56 e 70 dias após a aplicação (estádios R3 e R5, respectivamente), o que favoreceu o aumento de doenças foliares nos híbridos Impacto e P30K75. Observou-se redução na severidade das doenças, embora devido à longa estiagem, que houve pequena evolução das doenças. A incidência e a severidade das doenças têm 
aumentado muito, em decorrência, principalmente, de modificações no sistema de cultivo e na época de semeadura da cultura do milho, bem como da expansão da área cultivada para a região Centro-Oeste. Os cultivos de safrinha, juntamente com os da safra de verão, expõem a cultura do milho a condições climáticas muitas vezes favoráveis ao desenvolvimento de determinadas doenças. Além disso, a safrinha pode contribuir para a manutenção de inóculo de vários patógenos, que, posteriormente, podem infectar as lavouras da próxima safra (PINTO; ANGELIS ; HAB, 2004).

$\mathrm{Na}$ avaliação da AACPD para a severidade de doenças nos terços médio e superior, observou-se efeito significativo somente para a fonte de variação híbridos. O híbrido Impacto apresentou menor valor de AACPD no terço médio devido a maior tolerância à severidade de doenças, ao contrário do AG 7000 que apresentou maior valor (Tabela 3). Para a AACPD do terço superior das plantas, não foram constatadas diferenças significativas entre os tratamentos. A não significância da AACPD pode ser atribuida aos menores índices de precipitação registrados na safrinha, a partir de março de 2007, desfavorecendo assim o aparecimento e o aumento da severidade de doenças nas plantas de milho.

Tabela 3. Valores médios da área abaixo da curva de progresso de doença para severidade no terço médio e terço superior dos híbridos AG 7000, Impacto e P30K75 em função da aplicação de fungicida, na safrinha de 2007

\section{Híbridos}

AG7000

Impacto

P30K75
AACPD TM

91,98 a

$64,23 \mathrm{~b}$

$84,11 \mathrm{ab}$
AACPD TS

52,46 a

55,76 a

57,06 a

\section{Tratamentos}

\begin{tabular}{ccc}
\hline Test & $87,09 \mathrm{a}$ & $60,76 \mathrm{a}$ \\
VT & $81,81 \mathrm{a}$ & $56,01 \mathrm{a}$ \\
R1 & $73,83 \mathrm{a}$ & $56,08 \mathrm{a}$ \\
$\mathrm{VT}+\mathrm{R} 1$ & $77,71 \mathrm{a}$ & $47,51 \mathrm{a}$ \\
\hline CV $(\%)$ & 39,52 & 37,80 \\
\hline
\end{tabular}

*Médias seguidas de mesma letra minúscula na coluna e maiúscula na linha, dentro de cada variável, não diferem entre si pelo teste Tukey, a 5\% de probabilidade.

\section{Altura de plantas, altura de inserção da primeira espiga e acamamento}

Para a altura de plantas e de inserção da espiga, foram encontradas significâncias para a interação híbridos x épocas de aplicação. Pode-se constatar que as aplicações de fungicida proporcionaram maior altura de plantas de milho apenas no híbrido P30K75, devido à manutenção, por maior tempo da área foliar ativa, permitindo assim maior crescimento das plantas (Tabela 4).

Tabela 4. Valores médios de altura plantas e de inserção da primeira espiga (m), acamamento (\%), dos híbridos AG 7000, Impacto e P30K75 em função da aplicação de fungicida, na safrinha de 2007 (Continua)

\begin{tabular}{lcccc}
\hline Híbridos & Testemunha & VT & R1 & VT+R1 \\
\hline \multicolumn{5}{c}{ Altura de plantas $(\mathbf{m})$} \\
AG7000 & $1,6 \mathrm{Bab}$ & $1,9 \mathrm{Aa}$ & $1,9 \mathrm{Aa}$ & $1,9 \mathrm{Aa}$ \\
Impacto & $1,7 \mathrm{Ba}$ & $1,9 \mathrm{Aa}$ & $1,9 \mathrm{Aa}$ & $2,0 \mathrm{Aa}$ \\
P30K75 & $1,5 \mathrm{Bb}$ & $1,8 \mathrm{Ab}$ & $1,9 \mathrm{Aa}$ & $1,8 \mathrm{Aa}$ \\
\hline
\end{tabular}


Tabela 4. Valores médios de altura plantas e de inserção da primeira espiga (m), acamamento (\%), dos híbridos AG 7000, Impacto e P30K75 em função da aplicação de fungicida, na safrinha de 2007 (Conclusão)

\begin{tabular}{lcccc}
\hline & \multicolumn{4}{c}{ Altura inserção da primeira espiga (m) } \\
AG7000 & $0,9 \mathrm{Bb}$ & $1,0 \mathrm{Aa}$ & $1,0 \mathrm{Aa}$ & $1,0 \mathrm{Aa}$ \\
Impacto & $1,0 \mathrm{Aa}$ & $1,0 \mathrm{Aa}$ & $1,0 \mathrm{Aa}$ & $1,0 \mathrm{Aa}$ \\
P30K75 & $0,9 \mathrm{Ab}$ & $1,0 \mathrm{Aa}$ & $1,0 \mathrm{Aa}$ & $1,0 \mathrm{Aa}$ \\
\hline \multicolumn{5}{c}{ Acamamento $(\%)$} \\
AG7000 & $2,2 \mathrm{Aa}$ & $1,2 \mathrm{Ba}$ & $1,0 \mathrm{Ba}$ & $1,0 \mathrm{Bab}$ \\
Impacto & $2,7 \mathrm{Aa}$ & $1,0 \mathrm{Ba}$ & $1,2 \mathrm{Ba}$ & $0,7 \mathrm{Bb}$ \\
P30K75 & $2,2 \mathrm{Aa}$ & $1,5 \mathrm{Aa}$ & $1,2 \mathrm{Ba}$ & $1,7 \mathrm{Aba}$ \\
\hline
\end{tabular}

* Médias seguidas de mesma letra minúscula na coluna e maiúscula na linha, dentro de cada variável, não diferem entre si pelo teste Tukey, a 5\%, de probabilidade.

Segundo Ceccon et al., (2007), a altura de plantas não apresentou efeito significativo, em VT. O mesmo fato pode ser constatado para a altura de inserção de espigas do AG7000. Entre os híbridos, o Impacto apresentou maior inserção em relação ao P30K75, porém, nas aplicações de fungicida em R1 e VT+R1, não houve diferença significativa entre os híbridos para altura de plantas e de inserção de espiga. Mesmo apresentando valor médio de 1,5\% de acamamento, foi constatado efeito benéfico da aplicação do fungicida em VT+R1 para todos híbridos de milho (Tabela 4), como constatados por FANTIN; DUARTE ; SAWAZAKI (2005).

Na avaliação do peso de mil grãos, pôde-se constatar o efeito benéfico do uso de duas aplicações de fungicida, proporcionando maiores valores para essa característica, apenas para o híbrido Impacto. Para os demais híbridos, o emprego de uma aplicação de fungicida resultou peso de mil grãos similiar a duas aplicações de fungicida, (Tabela 5). Resultados semelhantes foram obtidos com aplicação em R1, para o AG7000, e VT e R1, para o P30K75. O efeito benéfico do fungicida pôde ser justificado por proporcionar maior tempo de permanência de área foliar fotossinteticamente ativa, auxiliando na produção de fotoassimilados e o posterior enchimento de grãos. Entre os híbridos de milho, o Impacto apresentou maior peso de mil grãos quando efetuaram aplicações de fungicida em R1 e em VT+R1.

Quando se avaliou o número de grãos por espiga, constataram-se maiores valores, para cada híbrido, quando se utilizaram duas aplicações de fungicida (VT+R1), pelo maior período efetivo do fungicida na cultura. Entre os híbridos de milho, destacam-se os valores obtidos pelo AG 7000 e P30K75, sendo superior ao Impacto quando se usou o fungicida, (Tabela5).

Tabela 5. Valores médios peso de mil grãos (g), número de grãos por espiga, grãos ardidos (\%) dos híbridos AG 7000, Impacto e P30K75 em função da aplicação de fungicida, na safrinha de 2007 (Continua)

\begin{tabular}{lcccc}
\hline Híbridos & Testemunha & VT & R1 & VT+R1 \\
\hline \multicolumn{5}{c}{ Peso de mil grãos (g) } \\
AG7000 & $139 \mathrm{Ca}$ & $161 \mathrm{Bab}$ & $175 \mathrm{Aab}$ & $180 \mathrm{Ab}$ \\
Impacto & $129 \mathrm{Db}$ & $155 \mathrm{Cb}$ & $181 \mathrm{Ba}$ & $192 \mathrm{Aa}$ \\
P30K75 & $138 \mathrm{Ba}$ & $165 \mathrm{Aa}$ & $166 \mathrm{Ab}$ & $174 \mathrm{Ab}$ \\
\hline \multicolumn{5}{c}{ Número de grãos por espiga } \\
AG7000 & $325 \mathrm{Db}$ & $426 \mathrm{Ca}$ & $437 \mathrm{Ba}$ & $446 \mathrm{Aa}$ \\
Impacto & $334 \mathrm{Da}$ & $403 \mathrm{Cb}$ & $416 \mathrm{Bb}$ & $436 \mathrm{Ab}$ \\
P30K75 & $336 \mathrm{Da}$ & $429 \mathrm{Ca}$ & $441 \mathrm{Ba}$ & $449 \mathrm{Aa}$ \\
\hline
\end{tabular}


Tabela 5. Valores médios peso de mil grãos (g), número de grãos por espiga, grãos ardidos (\%) dos híbridos AG 7000, Impacto e P30K75 em função da aplicação de fungicida, na safrinha de 2007 (Conclusão)

\begin{tabular}{llcll}
\hline & \multicolumn{3}{c}{ Grãos ardidos $(\%)$} & \\
AG7000 & $2,5 \mathrm{Aa}$ & $1,0 \mathrm{Bb}$ & $1,5 \mathrm{Ba}$ & $1,0 \mathrm{Ba}$ \\
Impacto & $2,5 \mathrm{Aa}$ & $1,2 \mathrm{Bab}$ & $1,0 \mathrm{Ba}$ & $1,5 \mathrm{Ba}$ \\
P30K75 & $2,7 \mathrm{Aa}$ & $2,0 \mathrm{Aa}$ & $1,0 \mathrm{Ba}$ & $1,0 \mathrm{Ba}$ \\
\hline
\end{tabular}

* Médias seguidas de mesma letra minúscula na coluna e maiúscula na linha, dentro de cada variável, não diferem entre si pelo teste Tukey, a 5\%, de probabilidade.

Quando analisou-se a presença de grãos ardidos, constatou-se que as médias dos híbridos não diferiram entre si, em relação às épocas de aplicações de fungicida em R1 e VT+R1. Observou-se também que para as médias das épocas de aplicação de fungicidas, todas as épocas foram superiores a testemunha que apresentou maior valor, exceto para aplicação de fungicida no híbrido P30K75, cujo valor foi semelhante ao obtido na testemunha (Tabela 5).

Esses resultados demonstram o efeito benéfico do uso de fungicida na melhoria da qualidade dos grãos. Conforme Juliatti et al. (2007), ocorreu redução na incidência de grãos ardidos pela aplicação de fungicidas via foliar, com maior eficiência do pyraclostrobin + epoxiconazole. Nas condições deste trabalho, esta é a primeira constatação de campo que as aplicações foliares de fungicidas têm um grande potencial na redução da severidade de doenças, aumentando o rendimento de grãos e melhorando sua qualidade. Também Feksa et al. (2004) observaram controle de cercosporiose com uso de pyraclostrobin + epoxiconazole e azoxystrobin, obtendo acréscimo no rendimento de grãos e redução na porcentagem de grãos ardidos (Tabela 5).

Devido à maior tolerância do híbrido Impacto a doenças foliares e as condições não favoráveis ao desenvolvimento dos patógenos (menor umidade relativa e baixa precipitação) não foram constatadas diferenças expressivas no rendimento de grãos entre a aplicação de fungicida e o valor obtido na testemunha. Os resultados obtidos para rendimento de grãos permitiram constatar presença da interação híbridos x época de aplicação (Tabela 6). A aplicação de fungicida proporcionou maiores rendimentos para o AG 7000 independente da época de aplicação. Para o híbrido P30K75, todas as épocas de aplicação diferiram da testemunha.

Tabela 6. Valores médios de rendimento de grãos $\left(\mathrm{kg} \mathrm{ha}^{-1}\right)$, rentabilidade $\left(\mathrm{R} \$ \mathrm{ha}^{-1}\right)$ dos híbridos $\mathrm{AG} 7000$, Impacto e P30K75 em função da aplicação de fungicida, na safrinha de 2007

\begin{tabular}{|c|c|c|c|c|}
\hline Híbridos & Testemunha & VT & $\mathbf{R} 1$ & VT+R1 \\
\hline & \multicolumn{4}{|c|}{ Rendimento de grãos (kg há $\left.{ }^{-1}\right)$} \\
\hline AG7000 & $2.817 \mathrm{Ba}$ & $3.585 \mathrm{Aa}$ & $3.692 \mathrm{Aa}$ & $3.915 \mathrm{Aa}$ \\
\hline Impacto & $2.932 \mathrm{Aa}$ & $3.131 \mathrm{Aa}$ & $3.346 \mathrm{Ab}$ & $3.414 \mathrm{Aa}$ \\
\hline \multirow[t]{2}{*}{ P30K75 } & $2.883 \mathrm{Ba}$ & $3.358 \mathrm{Aa}$ & $3.541 \mathrm{Aab}$ & $3.868 \mathrm{Aa}$ \\
\hline & \multicolumn{4}{|c|}{ Rentabilidade ( $\mathrm{R} \$ \mathrm{ha}^{-1}$ ) } \\
\hline AG7000 & 00,00 & 105,10 & 130,24 & 144,30 \\
\hline Impacto & 00,00 & $-27,50$ & 23,00 & 0,52 \\
\hline P30K75 & 00,00 & 37,00 & 80,00 & 230,00 \\
\hline
\end{tabular}

* Médias seguidas de mesma letra minúscula na coluna e maiúscula na linha, dentro de cada variável, não diferem entre si pelo teste Tukey, a 5\%, de probabilidade.

Aumentos semelhantes no rendimento de grãos em milho foram obtidos em trabalho realizado por Butzen (2008), testando o uso de propiconazole em três grupos de híbridos (susceptíveis, moderadamente susceptíveis e moderadamente resistentes) para o controle da cercosporiose. Nos híbridos susceptíveis, o 
incremento foi de 10\%; nos moderadamente susceptíveis de $12 \%$ e nos moderadamente resistentes de 17\%. Os maiores valores obtidos, com aplicação nos estádios V8+VT, devem-se, de acordo com Souza ; Braga, (2004), ao maior período efetivo do fungicida nas plantas de milho, proporcionado pelas duas aplicações. O valor médio obtido na testemunha foi inferior aos demais, demonstrando o potencial de resposta à adoção de fungicida na cultura do milho como destacado por Pinto; Angelis ; Hab (2004), principalmente, quando se efetuaram duas aplicações (BRITO et al., 2007 ).

Em cada época de aplicação de fungicida e na testemunha, não houve diferenças significativas entre os híbridos de milho para rendimento de grãos, exceto em R1, no qual o híbrido Impacto apresentou rendimento inferior ao AG 7000 (Tabela 6). Na avaliação da resposta dos híbridos à aplicação de fungicida, destacaram-se os valores encontrados com as aplicações VT + R1 nos híbridos AG7000 e P30K75, demonstrando o potencial do uso de fungicida na cultura do milho quando o objetivo é o aumento de rentabilidade. Sandine ; Fancelli (2000) e Fancelli ; Dourado-Neto (2003) constataram que ao se efetuarem duas aplicações de fungicidas propiconazole, difenoconazole, azoxystrobin e tebuconazole na cultura do milho nos estádios fenológicos de oito folhas e pré-emborrachamento, no controle de cercosporiose, obteram acréscimos de $27,7 \%$ a $38,9 \%$ no rendimento.

$\mathrm{Na}$ avaliação da rentabilidade da aplicação de fungicida em cada híbrido de milho, verificou-se que os maiores retornos foram obtidos com duas aplicações de fungicidas, acrescido da aplicação em R1 para o híbrido P30K75 (Tabela 6). Nesse aspecto, o uso de $0,5 \mathrm{~L} \mathrm{ha}^{-1}$ do fungicida em duas aplicações, proporcionou maior retorno econômico em relação ao emprego de $0,75 \mathrm{~L} \mathrm{ha}^{-1}$ em R1 e VT para o híbrido P30K75. Mesmo este híbrido apresentando maior tolerância à Cercospora zea-maydis, Puccinia polysora, por exemplo, o uso de fungicida proporcionou incremento no rendimento de grãos. O não uso de fungicida é justificado para o Impacto, que não apresentou rentabilidades expressivas com uso dessa tecnologia. Em trabalhos realizados por Silva et al. (2005), ao avaliarem o efeito do controle químico de doenças no híbrido AG 6018, com uso do fungicida azoxystrobin + cyproconazole em diferentes doses e épocas de aplicação, constataram que todos os tratamentos com fungicida proporcionaram aumento no rendimento de grãos (20\% em média), com melhor retorno econômico quando os fungicidas foram aplicados no estádio de sete folhas.

\section{CONCLUSÃO}

A aplicação de fungicida em condição de safrinha proporcionou acréscimos nos rendimentos de grãos do AG7000 e P30K75, com maiores rentabilidades em aplicações sequenciais (VT + R1).

Para todos os híbridos cultivados na safrinha, as aplicações de fungicida em VT+R1 proporcionaram redução na incidência de grãos ardidos e de acamamento.

Na safrinha, os índices de incidência e de severidade foram baixos, não havendo diferença entre a testemunha com os tratamentos que receberam aplicação de fungicida.

\section{REFERÊNCIAS}

BERGER, R.D. Comparison of Gompertz and logistic equations to describe plant disease progress. Phytopathology, St. Paul, v.71, p.716-719, 1981.

BRASIL, E.M. ; CARVALHO, Y. Comportamento de híbridos de milho em relação a Phaeosphaeria maydis em diferentes épocas de plantio. Pesquisa Agropecuária Brasileira. V.33, 1977-1981. p. 234239.1998. 
BRITO, A.H.et al. Efeito da cercosporiose no rendimento de híbridos comerciais de milho. Fitopatologia Brasileira, Brasília, v.32, p.472-479. 2007.

BUTZEN, S. Using Tilt for controlo f Gray leaf spot in cor. Disponível em:

http://www.pioner.com/usa/cropimanagement/national/tiltgrayleafspotintro.htm. Acesso em: 04 abr. 2008.

CAMPBELL, C.L.; MADDEN, L.V. Introduction to plant disease epidemiology. New York: John Wiley ; Sons, 1990. cap. 6, p. 107-128.

CASA; R.T.; REIS, E.M.; BLUM, M.M.C. Quantificação de danos causados por doenças em milho. Disponível em: http://www.ufv.br/dfp/workshop/Resumos/MilhoDanosEpidemiologia.pdf. Acesso em: 22 maio 2008.

CECCON, G.et al. Comportamento de genótiposde milho safrinha em duas épocas de semeadura, em Dourados, MS. In: SEMINÁRIO NACIONAL DE MILHO SAFRINHA. RUMO A ESTABILIDADE, 9. Anais...... Dourados, p. 311-316, 2007.

CRUZ, C.D. Programa GENES: aplicativo computacional em genética e estatística.

Viçosa: UFV, 1997. 442p.

EMBRAPA - EMPRESA BRASILEIRA DE PESQUISA AGROPECUÁRIA. Sistema brasileiro de classificação de solos. Rio de Janeiro, EMBRAPA, 1999. 412p.

EMBRAPA - EMPRESA BRASILEIRA DE PESQUISA AGROPECUÁRIA. Cultivo do milho: doenças. 2007. Disponível em: http://www.cnpms.embrapa.br/publicacoes/milho/doencas.htm. Acesso em: 06/03/2008.

FANCELLI, A. L.; DOURADO-NETO, D. Milho: estratégias de manejo para alta produtividade. Piracicaba. ESALQ/USP, 2003.208p.

FANTIN, G.M.; DUARTE, A.P.; SAWAZAKI, E. Controle químico de doenças foliares do milho. In: SEMINÁRIO NACIONAL DE MILHO SAFRINHA, 8, 1995. Assis. Anais... Campinas: Instituto Agronômico de Campinas, 2005. p.195-218.

FERNANDES, F.T.; OLIVEIRA, E. de. Principais doenças na cultura do milho. Sete Lagoas: (EMBRAPA-CNPMS), 1997. (Circular técnica, 26).

FERREIRA, D.F. Análises estatísticas por meio do Sisvar para Windows versão 4.0. In: REUNIÃO ANUAL DA REGIÃO BRASILEIRA DA SOCIEDADE INTERNACIONAL DE BIOMETRIA, 45. Anais... São Carlos: UFSCar, p.255-258, jul. 2000.

FEKSA, H.et al. Avaliação agrícola com tecnologia "BVO" versus fungicida visando o controle de Diplodia macrospora e Cercospora zea-maydis, nos híbridos DKB 214/DKB215 na região de Guarapuava/PR. FAPA - Cooperativa Agrária Mista Entre Rios Ltda. Safra 2002/2003. In: CONGRESSO NACIONAL DE MILHO E SORGO, 25, Anais... Cuiabá, 2004. 4p. (compact disc).

HILTY, J.W.; HADDEN, C.H.; GARDEN, F.T. Response of maize hybrids and inbred lines to gray leaf spot disease and the effects on yield in Tennessee. Plant Disease Reporter, Beltsviille, v.63, n.6, p.515$518,1979$.

JULIATTI, F.C.et al. Efeito do genótipo de milho e da aplicação foliar de fungicidas na incidência de grãos ardidos.Bioscience Journal, Uberlândia, v.23, n.2, p 34-41, 2007.

MORANDI, M.A.B.et al. Viabilidade do uso de fungicidas no controle da cercosporiose do milho.

Fitopatologia Brasileira, Brasília, v.27, p.S138, 2002. Suplemento. 
PEREIRA, O.A.P.; SILVA, H.P.; REZENDE, I.C. Perda da produção de milho casada por Exserohilm turcicum (Pass.) Leonard; Sgss. Fitopatologia Brasileira, Brasília, v.18, p.333, 1993. Suplemento

PINTO, N.F.J.de.A.; ANGELIS, B.de.; HAB, E. M.H. Avaliação da eficiência de fungicidas no controle da cercosporiose (Cercospora zea-maydis) na cultura do milho. Revista Brasileira de Milho e Sorgo, Sete Lagoas, v.3, n.1, p.139-145, 2004.

SANDINE, I.E. ; FANCELLI, A.L. Milho: estratégias de manejo para a região sul. Guarapuava: Fundação Agrária de Pesquisa Agrária de Pesquisa Agropecuária. 2000. 209 p.

SAWAZAKI, E.et al. Reação de cultivares de milho à Phaeosphaeria no estado de São Paulo. Pesquisa Agropecuária Brasileira. v. 32, p. 585-589, 1997.

SHANER, G.; FINNEY, R. E. The effect of nitrogen fertilization on the expression of slow-mildewing resistance in knox wheat. Phytopathology, St. Paul, v. 67, n. 8, p. 1051-1056, Aug. 1977.

SILVA, O.C.da et al. Efeito do momento da aplicação e dose do fungicidda azoxystrobin+cyproconazole no controle das doenças foliares do milho. Fitopatologia Brasileira, v.30, p.S108, 2005. Suplemento.

SOUZA, P.M. de; BRAGA, M.J. Aspectos econômicos da produção e comercialização do milho no Brasil. In: GALVÃO, J.C.C.; MIRANDA, G.V. Tecnologias de produção do milho. Viçosa: UFV, 2004. p.13-53.

WARD, J.M.J; LAING, M.D.; RIJKENBERG, F.H.J. Frequency and timing of fungicide applications for the control of gray leaf spot in maize. Plant Disease, St. Paul, v.81, n.1, p.41-48, 1997. 
